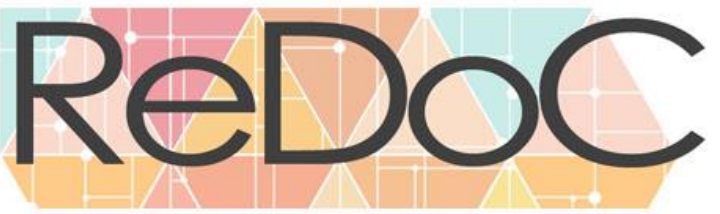

Revista Docência e Cibercultura

\title{
UPRADE NA INTERFACE DO FORMULÁRIO ONLINE DA GOOGLE: AMBIENTE COLABORATIVO DE APRENDIZAGEM
}

\section{UPGRADE TO GOOGLE'S ONLINE FORM INTERFACE: COLLABORATIVE LEARNING ENVIRONMENT}

\section{UPGRADE EN LA INTERFAZ DEL FORMULARIO ONLINE DE GOOGLE: AMBIENTE COLABORATIVO DE APRENDIZAJE}

\author{
Ana Patrícia Lima Sampaio ${ }^{1}$
}

Maria Inez Pereira de Alcântara ${ }^{2}$

\begin{abstract}
Resumo: Este artigo é decorrente de observações, registros e análises de estudos realizadas a partir de uma oficina pedagógica onde foi utilizado o aplicativo Google para elaboração e compartilhamento de formulários de avaliação. Teve como finalidade potencializar o uso do formulário da Google no ambiente colaborativo da plataforma $e$ Proinfo. O percurso metodológico foi baseado na abordagem mista que combina técnicas de pesquisa quantitativa e qualitativa. A concretização do estudo aconteceu durante a realização do curso professor na era digital, disciplina criação de formulários online utilizando como recurso de interação e colaboração o Ambiente Colaborativo de Aprendizagem (e-Proinfo), o qual contou com a participação de 26 (vinte e seis) professores, para os quais foi aplicado um questionário com perguntas diretas. O estudo mostrou que as tecnologias educacionais despontam como alvissareiras e propícias para a melhoria do processo de ensino e aprendizagem no contexto atual caracterizado por intensas modificações sociais, culturais, educacionais e tecnológicas, entretanto, o estudo também apontou a necessidade de estruturas mais adequadas para que as formações aconteçam com mais êxito.
\end{abstract}

Palavras-chave: formação continuada; formulários online; plataforma virtual.

Abstract: This article is based on observations, records and analysis of studies carried out from a pedagogical workshop where the Google application was used to elaborate and share assessment forms. It was intended to enhance the use of the Google form in the collaborative environment of the $e$-Proinfo platform. The methodological approach was based on a mixed approach that combines quantitative and qualitative research techniques. The implementation of the study took place during the course of the teacher in the digital age, a discipline that created online forms using the Collaborative Learning Environment (e-Proinfo) as an interaction and collaboration resource 26 (twenty-six )

Submetido em: 24/02/2018 - Aceito em: 28/04/2018 - Publicado em: 25/06/2018.

1 Professora da SEDUC/CEPAN/NTE/AM. Mestranda em Ciências da Educação área Tecnologia Educativa - Universidade do Minho - Portugal. E-mail anapatricia@ seduc.net.

${ }^{2}$ Pedagoga da SEDUC/CEPAN/NTE/AM. Doutora em Ciências da Educação área Tecnologia Educativa Universidade de Trás- os - Montes e Alto Douro - UTAD - Portugal. E-mail maria.alcantara@seduc.net. 


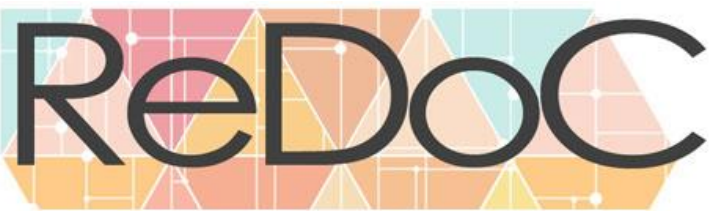

Revista Docência e Cibercultura

teachers, for whom a questionnaire with direct questions was applied. The study showed that educational technologies are emerging as a good way to improve the teaching and learning process in the current context characterized by intense social, cultural, educational and technological changes, however, the study also pointed to the need for more adequate structures to the formations happen more successfully.

Keywords: training; online forms; virtual platform.

Resumén: Este artículo es fruto de observaciones, registros y análisis de estudios realizados a partir de una oficina pedagógica donde fue utilizado el aplicativo Google para la elaboración e intercambio de formularios de evaluación. Tuvo como finalidad incentivar el uso del formulario de Google en un ambiente colaborativo de la plataforma e-Proinfo. El camino metodológico se basó en un abordaje mixto que combina técnicas de investigación cuantitativas y cualitativas. La concretización del estudio se dio durante el curso profesor en la era digital, disciplina creación de formularios online utilizando como recurso de interacción y colaboración el Ambiente Colaborativo de Aprendizaje (eProinfo), el cual contó con la participación de 26 (veintiséis) profesores, para los cuales fue aplicado un cuestionario con preguntas directas. El estudio mostró que las tecnologías educacionales se presentan como una oportunidad para la mejoría del proceso de enseñanza y aprendizaje en el contexto actual caracterizado por intensas modificaciones sociales, culturales, educacionales y tecnológicas, sin embargo, el estudio también apuntó la necesidad de estructuras más adecuadas para que las formaciones sucedan con éxito.

Palabras clave: entrenamiento; formularios en línea; plataforma virtual.

\section{INTRODUÇÃO}

Nos dias atuais, vive-se um período caracterizado pelas transformações que acompanham as tecnologias de informação e comunicação (TIC) bem como sua inserção na chamada sociedade da informação. $O$ estudo foi direcionado pelas inquietações epistemológicas sobre aplicabilidade do uso do formulário da Google em processos de ensino e aprendizagem e a possibilidade de fomentar atitudes colaborativas no universo da interatividade ${ }^{3}$.

Para tanto o objetivo principal foi potencializar o uso do formulário da Google no ambiente colaborativo da plataforma e-Proinfo.

\footnotetext{
${ }^{3}$ É um diálogo entre o homem permeado pela máquina, que permitem conexões em tempo real, ou seja, um tipo de relação tecnossocial.
}

\begin{tabular}{l|l|l|l|l|l|l|} 
(C) Redoc & Rio de Janeiro & v.2 & n.2 & p. 52 & Maio/Agosto. 2018 & ISSN 2594-9004
\end{tabular}




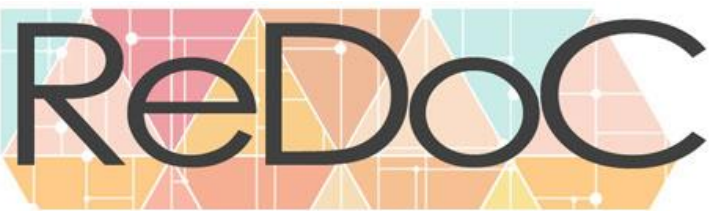

Revista Docência e Cibercultura

Quanto a metodologia, optou-se pela pesquisa de abordagem mista que combina técnicas de pesquisa quantitativa e qualitativa. A principal diferença entre esses dois tipos de pesquisa é que enquanto a quantitativa se baseia em números e cálculos matemáticos, a pesquisa qualitativa tem base no caráter subjetivo, usando narrativas escritas ou faladas.

Creswell e Plano Clark (2011) definem métodos mistos como um procedimento de coleta, análise e combinação de técnicas quantitativas e qualitativas em um mesmo desenho de pesquisa. O pressuposto central que justifica a abordagem multimétodo é o de que a interação entre eles fornece melhores possibilidades analíticas.

A concretização do estudo aconteceu durante a realização do curso professor na era digital, disciplina criação de formulários online utilizando como recurso de interação e colaboração o Ambiente Colaborativo de Aprendizagem (e-Proinfo), o qual contou com a participação de 26 (vinte e seis) professores, para os quais foi aplicado um questionário com perguntas diretas.à oficina pedagógica que resultou na construção de materiais pedagógicos, como exemplo, criação de protótipos de avaliações online. Os protótipos foram inseridos no ambiente colaborativo e compartilhados entre os cursistas.

O estudo revelou que as tecnologias ligadas à educação promovem a motivação, interação e a melhoria do processo de ensino e aprendizagem. Além disso, manifestou a necessidade de formação continuada dos profissionais da educação quanto ao uso das tecnologias educacionais, bem como a emprego destas ferramentas no fazer pedagógico na ambiência da sala de aula.

\section{AMBIENTE COLABORATIVO DE APRENDIZAGEM DA PLATAFORMA $e$ - Proinfo}

No contexto atual, a Educação enfrenta um momento de muitas transformações, principalmente com a inserção das novas tecnologias digitais no seu cotidiano. Uma destas transformações é a utilização das plataformas virtuais, no caso específico o Ambiente Colaborativo de Aprendizagem (e-Proinfo) com interação não apenas entre professores e alunos, mas também entre os próprios alunos. Além disso, significa revelar as variadas acepções de construção do conhecimento, modernizando e favorecendo a comunicação e interação no ensino a distância. 


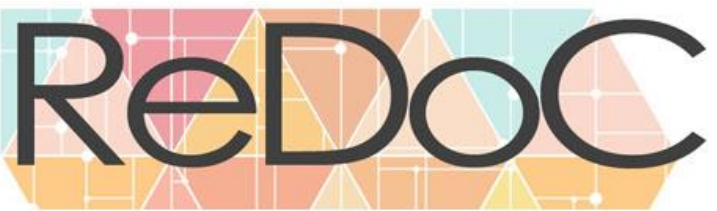

Revista Docência e Cibercultura

Em consonância a esse novo cenário, o Ambiente Colaborativo de Aprendizagem vem tornando-se um lócus de construção coletiva do conhecimento promovendo a aprendizagem colaborativa, através das ferramentas de comunicação e de colaboração online.

Assim sendo, através do credenciamento, o aluno pode ter acesso aos conteúdos das disciplinas (que são divididas por módulos) e interagir com colegas, professores e demais participantes do curso. $\mathrm{O}$ acesso pode ser feito a qualquer hora, e o usuário pode postar comentários, enviar arquivos e participar de chats e fóruns (SILVA, 2010, p.3). Para melhor compreensão apresentaremos a seguir o layout (figura 1) do ambiente virtual da plataforma e-Proinfo do curso Professora na Era Digital disciplina Criando formulários online da Google.

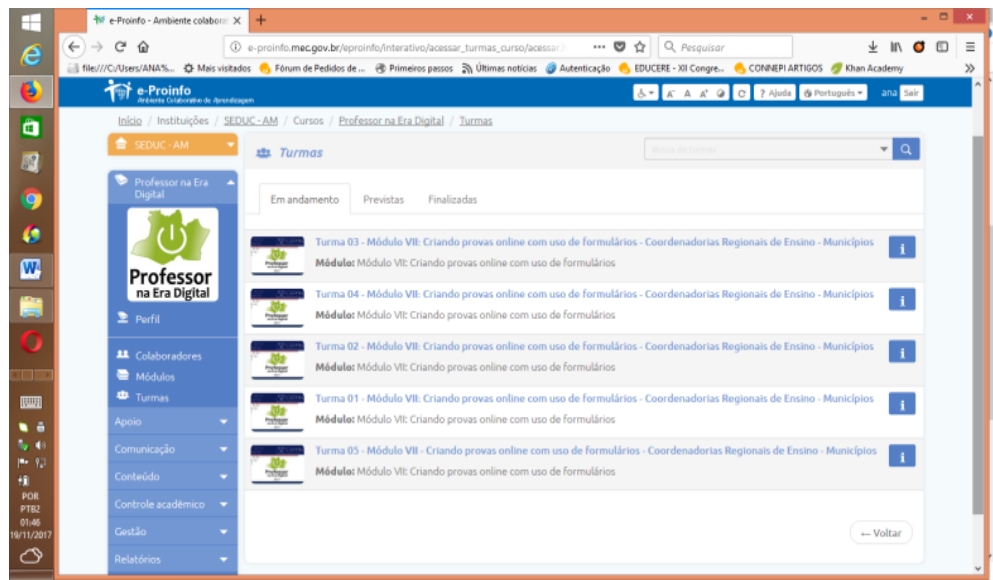

Figura 1: Captura da interface do ambiente virtual da plataforma e-Proinfo

Fonte: elaborado pelas autoras (2017)

Em termos gerais, a plataforma $e$-Proinfo ${ }^{4}$ composto por ferramentas síncronas (os alunos devem está conectados em tempo real) e assíncronas (as interações ocorrem em dias e horários definidos) como: fórum de discussão, tira-dúvidas, bate-papo, e-mail, materiais didáticos disponibilizados como apoio teórico e prático. É importante destacar que um ambiente virtual envolve um contexto mais amplo que puramente a utilização de

${ }^{4}$ Programa Nacional de Tecnologia Educacional (Proinfo) - e-proinfo.mec.gov.br 


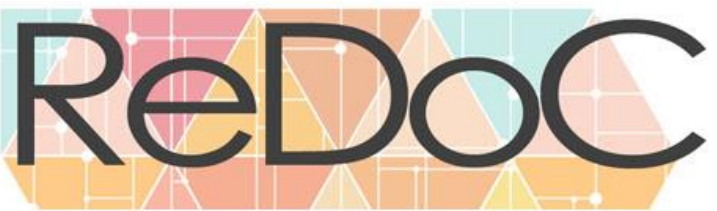

Revista Docência e Cibercultura

tecnologia, que possibilita que se compartilhem ações, interaja professor, tutor e aluno e que todos atuam simultaneamente.

As principais ferramentas síncronas e assíncronas utilizadas no curso Professor na Era Digital da disciplina Criando formulários online da Google pelo professor e alunos foram:

\section{Ferramentas síncronas:}

$\checkmark$ Chat ou salas de bate-papo: o professor e o aluno precisam está conectados em tempo real para participarem da discussão. O pensamento de Mattar (2012) sugere que "[...] é interessante que sejam propostos, antes do chat, alguns temas, textos para leituras, links, vídeos, etc., para que os participantes cheguem preparados para o debate" (MATTAR, 2012, p.118).

Com essa perspectiva, também é possível conversar reservadamente com os colegas e dividir a turma em grupos para realização de alguma atividade.

\section{Ferramentas assíncronas:}

$\checkmark$ Fórum de discussão e tira dúvidas: os assuntos exposto nos fóruns são acompanhados pelo professor ou tutor, os comentários dos alunos são dados feedback pelo do professor ou tutor. Como no caso dos chats, o fórum pode pressupor a leitura de um texto ou propor um tema para debate ou tirar dúvidas de alguma atividade. De acordo com Mattar (2012) “[...] os fóruns podem ser moderados (quando o professor ou o tutor precisam ler os comentários dos alunos antes de publicá-los) ou livres (quando os comentários são automaticamente publicados, sem a mediação do professor ou tutor)" (MATTAR, 2012, p.120).

$\checkmark$ Questionário: é um repositório de questões elaborado pelo professor, as mesmas são utilizadas nas atividades das turmas direcionadas a cada módulo do curso. As questões podem ser elaboradas de diferentes formatos: múltipla escolha certo/errado e questões discursivas.

Por conseguinte, Litwin (1997), enfatiza que "com as novas tecnologias o trabalho adquire uma nova conformação: como exemplo as qualificações dos educadores quanto ao uso das Tecnologias de Informação e Comunicação - TIC, aprender novos modelos e práticas educacionais e produção de novos conhecimentos”.

\begin{tabular}{l|l|l|l|l|l|l|} 
(C) Redoc & Rio de Janeiro & v.2 & n.2 & p. 55 & Maio/Agosto. 2018 & ISSN 2594-9004 \\
\hline
\end{tabular}




\section{FORMAÇÃO CONTINUADA}

Falar da formação continuada requer necessariamente que se fale da formação inicial de professores. A formação inicial diz respeito à primeira graduação cujo papel é crucial para a preparação profissional, pois é nela que os professores devem se apropriar de conhecimentos e experimentar, em seu próprio processo de aprendizagem, o desenvolvimento de competências necessárias para atuar nesse novo cenário. A formação de um profissional de educação tem que estimulá-lo a aprender o tempo todo, a pesquisar, a investir na própria formação e a usar sua inteligência, criatividade, sensibilidade e capacidade de interagir com outras pessoas.

Quanto à interação recorremos a Zabala (2002), pois ele apresenta três tipos de conhecimentos ambos relacionados entre si: conhecimento conceitual, procedimental e atitudinal dos três, afirma o autor, que o mais importante é o atitudinal. Desta feita, concordamos com o entendimento do autor no que se refere a relevância do conhecimento atitudinal, visto que este, é o resultado da interação entre o conceito e procedimento.

Além dos conceitos estabelecidos por Zabala, citamos os pilares da educação para o Séc. XXI, aprender a aprender, aprender a ser, aprender a fazer e aprender a conviver.

A Lei de Diretrizes e Bases da Educação Nacional de 1996 (LDBEN) em consonância a Constituição Brasileira de 1988, dedica um capítulo específico à formação dos profissionais da educação, com destaque para os professores. Art. 61. "A formação de profissionais da educação, de modo a atender aos objetivos dos diferentes níveis e modalidades de ensino e as características de cada fase do desenvolvimento do educando, terá como fundamentos: I a associação entre teorias e práticas, inclusive mediante a capacitação em serviço; II aproveitamento da formação e experiências anteriores em instituições de ensino e outras atividades". 
O Art. 62 destaca "A formação de docentes para atuar na educação básica farse-á em nível superior, em curso de licenciatura, de graduação plena, em universidades e institutos superiores de educação, admitida, como formação mínima para o exercício do magistério na educação infantil e nas quatro primeiras séries do ensino fundamental, a oferecida em nível médio, na modalidade Normal”.

No Art. 63, descreve "Os institutos superiores de educação manterão: I -cursos formadores de profissionais para a educação básica, inclusive o curso normal superior, destinado à formação de docentes para a educação infantil e para as primeiras séries do ensino fundamental; II - programas de formação pedagógica para portadores de diplomas de educação superior que queiram se dedicar à educação básica; III -programas de educação continuada para os profissionais de educação dos diversos níveis”.

A partir das reflexões sobre a formação inicial discorreremos sobre a formação continuada de professores. Amparada nos dispositivos legais citados anteriormente e o decreto $N^{\circ} 8.752$, de 9 de maio de 2016 que dispõe sobre a política Nacional de Formação dos Profissionais da Educação Básica e a Portaria No 1.328, de 23 de setembro de 2011 que institui a Rede Nacional de Formação Continuada dos Profissionais do Magistério da Educação Básica Pública.

Outro documento legal em vigência refere-se ao Plano Nacional de Educação (PNE) instituído pela Lei $\mathrm{N}^{\mathrm{o}}$ 13.005/2014, em vigor desde o ano de sua promulgação com prazo de dez anos para ser implantado, possui 20 metas estruturantes determinadas pelo governo federal para garantir o direito à educação de qualidade. A Meta 16 refere-se à formação continuada dos profissionais da educação a qual destaca: "formar, em nível de pós-graduação, 50\% dos professores da Educação Básica, até o último ano de vigência deste PNE, e garantir a todos os (as) profissionais da Educação Básica formação continuada em sua área de atuação, considerando as necessidades, demandas e contextualizações dos sistemas de ensino".

De acordo, com o observatório PNE atualmente, apenas 31,4\% dos professores da Educação Básica possuem Pós-Graduação, segundo dados do Censo Escolar. A deficiência na formação inicial de nossos docentes é um dos grandes entraves na melhoria da qualidade educação. Nesse sentido, a formação continuada representa um grande 


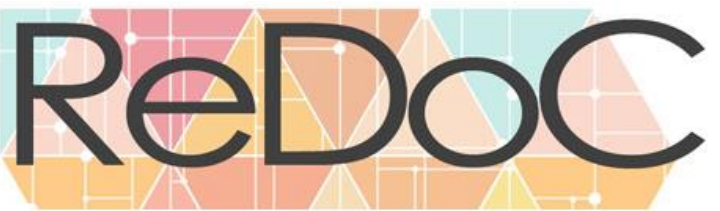

Revista Docência e Cibercultura

aliado, na medida em que possibilita que o professor supra as lacunas na sua formação inicial ao mesmo tempo em que se mantém em constante aperfeiçoamento em sua atividade profissional. Fonte: MEC/Inep/DEED/Censo Escolar.

O relatório de avaliação 2013-2016 quadrienal 2017 da Coordenação de Aperfeiçoamento de Nível Superior - CAPES, aponta a evolução da forma piramidal de classificação dos Programas da Área desde sua primeira avaliação, em 2007, com 11 Programas, até a avaliação atual, com 140 Programas. Partindo de um ponto em que havia apenas dois programas referência nota 5, em 2007, a Área foi ampliando a qualidade dos programas sem, no entanto, ter reunido características de excelência em 2010 sem preencher o extrato de notas 6 e 7. A Área credenciou seus 4 primeiros programas 7 nota 6 na avaliação trienal de 2013; na avaliação de 2017 a Área já se apresentou madura, com 23 programas indicados para nota 5 pela CA e sendo 19 confirmados pelo CTC (11 acadêmicos e 08 profissionais), com condições de excelência para indicar seus 3 primeiros programas nota 7 (um deles confirmado pelo CTC-ES), e para ampliar para 7 programas seu extrato de notas 6 (o CTC-ES confirmou 5 programas na nota 6). A trajetória permite afirmar, com segurança, que o processo de construção e de consolidação da Área de Ensino foi concluído, e que agora seu contínuo aperfeiçoamento será tarefa da comunidade nela reunida.

A maioria das funções docentes com pós-graduação possui somente especialização. Do total de funções docentes em 2014, eram 30,0\% com especialização, $1,8 \%$ com mestrado e $0,3 \%$ com doutorado - a soma dos percentuais excede o dado de 31,4\% com pós-graduação, pois há docentes que possuem mais de um tipo de pósgraduação.

A etapa/modalidade com maior percentual de funções docentes com pósgraduação em 2014 foi a Educação Especial, com 56,2\%. Por outro lado, a Educação Infantil apresentava o percentual mais baixo, 23,9\%. Os dados também revelam que o indicador é melhor na rede pública (34,0\% em 2014, contra 23,6\% na rede privada), mais 


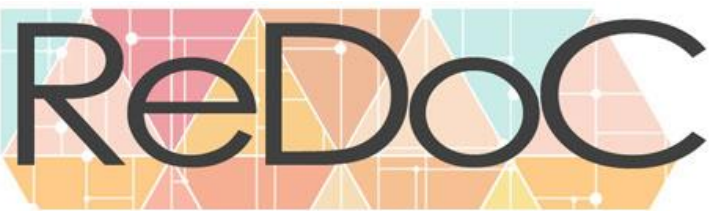

Revista Docência e Cibercultura

especificamente na rede federal $(70,1 \%)$, seguida da rede estadual $(38,2 \%)$ e da rede municipal $(31,6 \%)$.

Com base no exposto, verifica-se a importância da formação continuada para o aprimoramento dos saberes adquiridos durante a formação inicial. A busca de conhecimentos deve ser prioridade para os profissionais do ensino que procuram modernização dentro de sua área de atuação. Sendo assim, o trabalho ora apresentado oferece aos professores da rede pública maiores possibilidades na condução do seu fazer pedagógico incrementado pelo saber fazer.

\section{GOOGLE DRIVE: formulários}

O potencial educativo das ferramentas da Web 2.0 viraram tendências nas "novas tecnologias digitais" abrindo um leque de possibilidade e impactando a produção e troca de novos conhecimentos.

Compartilhando desse pensamento, Roesler (2012) enfatiza que a Web 2.0, tem se constituído em um grande banco de dados para aqueles que interagem em busca de conhecimentos e informações. Suas ferramentas, como exemplos os blogs, ferramentas da Google e as páginas wikis, podem e devem ser explorados e incentivados pelos professores como meios de produção e troca de saberes.

Nessa perspectiva, o aplicativo Google Drive conta com ferramentas de interação e colaboração acessíveis, para auxiliar a transposição de conteúdos e avaliações para o mundo de significados do educando (ALMEIDA, 2016, p.2) na construção do processo de ensino e aprendizagem em múltiplos planos. Todo esse aporte tecnológico é utilizado com recurso pedagógico.

É importante ressaltar que essa ferramenta de inovação pedagógica "formulários da Google", ou "Google Forms" permite de maneira simples e fácil coletar informações, criar diagnóstico dos alunos, realizar uma pesquisa rápida e aplicar autodiagnostico onde os alunos possam identificar os seus estilos de aprendizagem impactando positivamente nos métodos ativos de ensino. 


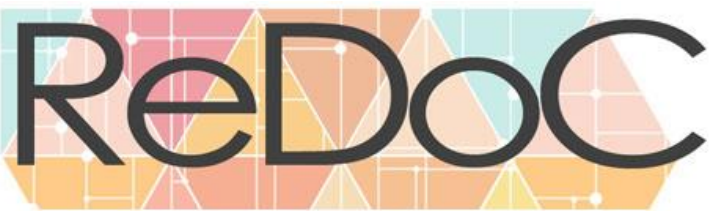

Revista Docência e Cibercultura

Por conseguinte, a facilidade de realizar um questionário e coletar automaticamente os dados em uma planilha torna-se eficiente quando o professor recorre aos dados estatísticos da ferramenta apresentando o layout limpo e intuitivo. De posse dos resultados em tempo real, o professor poderá realizar suas inferências em seus planos de aula, pois, saberá em tempo real onde o aluno está com déficit de aprendizagem (MALVEIRA, 2016, p.2), a partir daí desenvolver novas estratégias de aprendizagem.

Desta feita, ao longo dos últimos anos, os formulários da Google vêm recebendo diversas atualizações para ajudar os professores e empresas a fazerem suas pesquisas bem estruturadas, com novas opções de tema do próprio formulário ou criar seus próprios temas personalizados.

A figura 2 apresenta os recursos do formulário da Google que compõe a extensão da conta de e-mail do professor e dos e-mails que foram criados pelos alunos de cada turma do curso professor na Era Digital, disciplina Criando formulários online da Google.

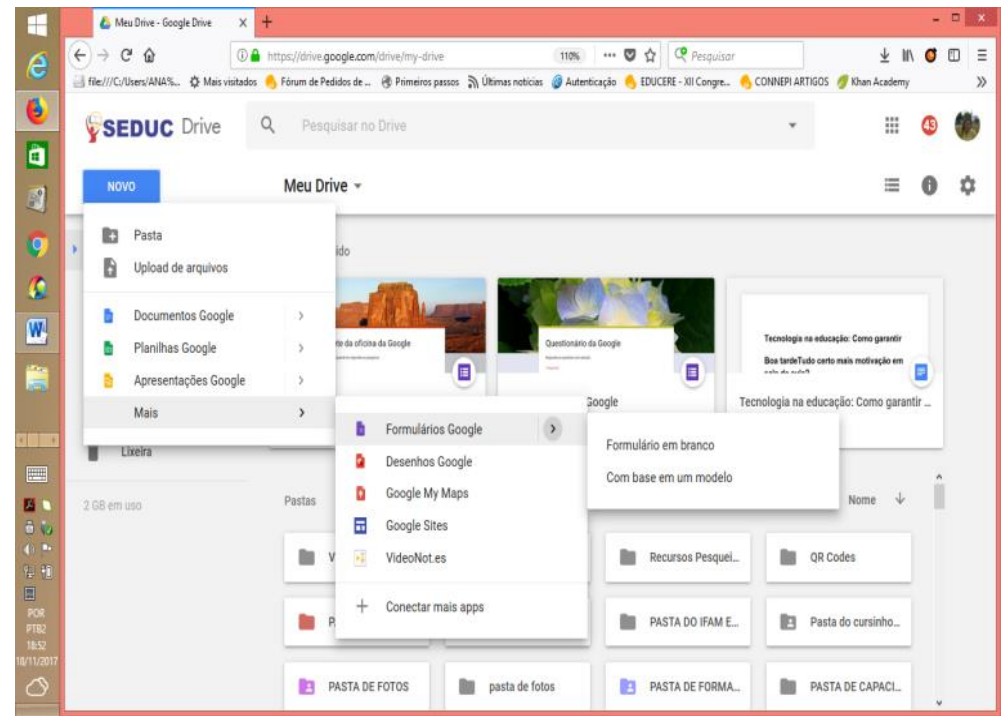

Figura 2: Captura da tela dos recursos do formulário da Google

Fonte: elaborado pelas autoras (2017)

Assim sendo, é oportunizado aos alunos respondessem os formulários online de diversas localizações geográficas, permitindo que a coleta e organização das informações sejam automatizadas, com isso, otimizando tempo e espaço do professor na preparação 


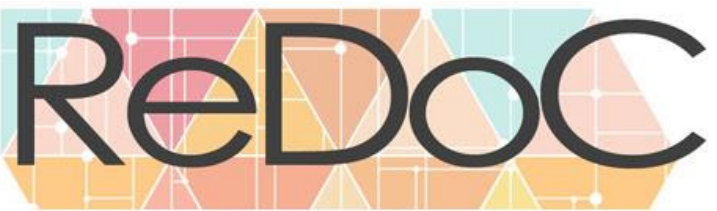

Revista Docência e Cibercultura

das suas avaliações. Verifica-se também, a não exposição dos pesquisados à influência da pessoa do pesquisador, contemporizando o anonimato das respostas.

Esta metodologia deve ser aproveitada em contexto educativo, pois motivar a participação de um grande número de professores e alunos, tornando-os participantes principais do processo e não mais meros coadjuvantes, proporcionando possível a construção do conhecimento, principal objetivo do processo educacional.

\section{METODOLOGIA}

Este curso foi realizado na modalidade semipresencial, o qual possui 2 (dois) momentos à distância exigindo que os interlocutores estejam conectados mediante o ambiente colaborativo de aprendizagem e presencial por via de oficina pedagógica.

Segundo Candau (2011), a oficina constitui um espaço de construção coletiva do conhecimento, de análise da realidade, de confronto e troca de experiências. A atividade, a participação, a socialização da palavra, a vivência de situações concretas através de sociodramas, análise de acontecimentos, a leitura e a discussão de textos, o trabalho com distintas expressões da cultura popular, são elementos fundamentais na dinâmica das oficinas pedagógicas.

Desta feita, foi desenvolvido esse trabalho com 5 (cinco) turmas de, no mínimo, 38 (trinta e oito) e, o máximo 60 (sessenta) docentes com a intenção de tornar as aulas motivadoras e ao mesmo tempo enriquecedoras para a aprendizagem dos alunos, cuja parte empírica e análise obedeceram aos seguintes momentos:

Momentos da oficina

$1^{\circ}$ Momento

a) Realização de pesquisa bibliográfica;

b) Produção de materiais e vídeos aulas;

c) Preparação da sala virtual da disciplina Criando Formulário Online no Ambiente Colaborativo de Aprendizagem;

d) Disponibilização do ambiente virtual de aprendizagem para os cursistas.

$2^{\circ}$ Momento

a) Encontro presencial com os cursistas;

\begin{tabular}{l|l|l|l|l|l|l|} 
(C) Redoc & Rio de Janeiro & v.2 & n.2 & p. 61 & Maio/Agosto. 2018 & ISSN 2594-9004 \\
\hline
\end{tabular}


b) Realização da oficina com carga horário total de $8 \mathrm{~h}$;

c) Disponibilização do fórum: apresentação pessoal e tira dúvidas e os questionários elaborados pelos cursistas, através do formulário da Google com carga horária total de $12 \mathrm{~h}$.

d) A interação das atividades pelos cursistas no ambiente colaborativo de aprendizagem.

e) Feedback das produções dos cursistas através de um questionário online da Google.

\section{$3^{\circ}$ Momento}

Neste trabalho foi utilizada uma pesquisa de abordagem mista que combina técnicas de pesquisa qualitativa com quantitativa [...] como são duas abordagens com características antagônicas, elas se combinam de forma que uma prevalecerá sobre a outra ao mesmo tempo em que podem se complementar na apresentação de resultados (CRESWELL, 2007, p.27). A principal diferença entre esses dois tipos de pesquisa é que enquanto a quantitativa se baseia em números e cálculos matemáticos, a pesquisa qualitativa tem base no caráter subjetivo, usando narrativas escritas ou faladas. A pesquisa quantitativa reúne dados que podem ser codificados de forma numérica.

Os dados da pesquisa foram coletados através de questionário com questões fechadas disponibilizadas online através do aplicativo Google.

\section{RESULTADOS E DISCUSSÕES}

Durante o desenvolvimento da criação do formulário da Google, foi possível perceber o envolvimento dos 26 (vinte e seis) ou correspondente há $10,50 \%$ do universo de 248 (duzentos e quarenta e oito) "professores-cursistas" participantes, os quais se mostraram entusiasmados, motivados e incentivados pela maneira que atividade foi conduzida, episódio evidenciado nos recortes das falas a seguir:

[...] Avaliação online criada por mim contendo 10 questões de Geografia, inclusive já enviadas para 360 alunos do $3^{\circ}$ ano da Escola Estadual Nossa Senhora de Nazaré, em Manacapuru, onde para minha surpresa 324 alunos, ou seja, 90\% responderam o respectivo teste [...] (Entrevista do professor F1). 
[...] Olá, Professor F1! Respondi ao seu formulário, acho que não fui muito bem, não...rsrs...Bom, esta atividade é muito rica e inovadora. É uma maneira bem prática no uso de tecnologias na educação. Tenho certeza que os alunos adoram essa ferramenta [...] (Entrevista do professor F2).

[...] Segue abaixo o link para acesso a minha avaliação de matemática para alunos do $2^{\circ}$ ano, estou muito feliz, pois, não conhecia esta ferramenta, espero corresponder as expectativas dos colegas que queiram acessar o link e responder essa avaliação que é a primeira de muitas que pretendo fazer [...] (Entrevista do professor F5).

[...] Estou encantada com a ferramenta, foi a primeira vez que trabalhei com ela, como é prática quando temos uma internet boa [...] (Entrevista do professor F8).

Os relatos revelam o quanto aprendizagem foi significativa para os professores cursistas, bem como para seus respectivos alunos, conforme o depoimento do professor F1. Para Ausubel (2003) aprender significativamente é ampliar e reconfigurar ideias já existentes na estrutura mental e com isso ser capaz de relacionar e acessar novos conteúdos.

Outro ponto a destacar foi à motivação dos estudantes em responder o "teste", o que demonstra que para aprender significativamente, segundo Moreira (2012), é necessário essencialmente duas condições 1) o material de aprendizagem deve ser potencialmente significativo e 2) o aprendiz deve apresentar uma predisposição para aprender.

De acordo com o autor a primeira condição sugere: 1) que o material de aprendizagem (livros, aulas, aplicativos,...) tenha significado lógico (isto é, seja relacionável de maneira não-arbitrária e não-literal a uma estrutura cognitiva apropriada e relevante) e 2) que o aprendiz tenha em sua estrutura cognitiva ideias-âncora relevantes com as quais esse material possa ser relacionado. Quer dizer, o material deve ser relacionável à estrutura cognitiva e o aprendiz deve ter o conhecimento prévio necessário para fazer esse relacionamento de forma não-arbitrária e não-literal.

Na concepção do Professor F2 a atividade foi rica, inovadora, revelou ser uma maneira prática da utilização da ferramenta na educação, enfatizando mais uma vez a importância da inteligência tecnológica como artefato rico em possibilidades educativas. A inteligência tecnológica é um termo utilizado por Lévy (2010), segundo ele a inteligência do todo não resulta mais mecanicamente de atos cegos e automáticos, pois é

\begin{tabular}{l|l|l|l|l|l|l|} 
(C) Redoc & Rio de Janeiro & v.2 & n.2 & p. 63 & Maio/Agosto. 2018 & ISSN 2594-9004
\end{tabular}




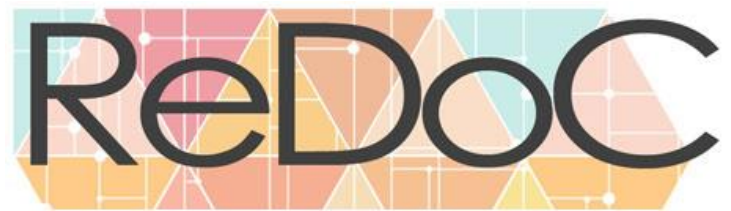

Revista Docência e Cibercultura

o pensamento das pessoas que pereniza, inventa e põe em movimento o pensamento da sociedade.

A análise e interpretação tiveram como parâmetro o questionário online respondidos pelos cursistas. Após analisar as respostas, foi feita uma releitura, comparando os dados coletados com o referencial teórico conforme indicam os gráficos a seguir.

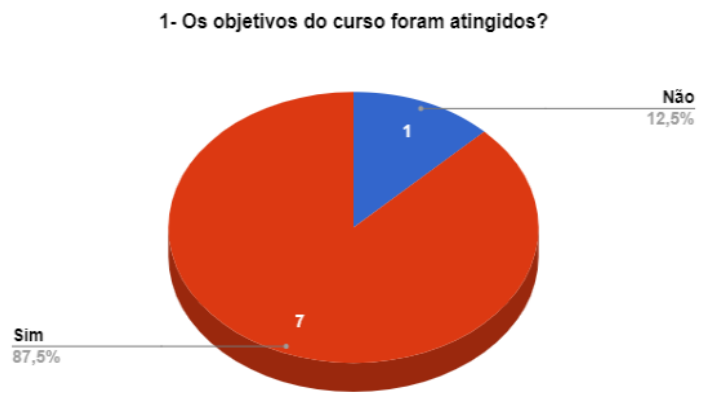

Gráfico 1: Os objetivos do curso foram atingidos? Fonte: elaborado pelas autoras (2017)

O gráfico 1 mostra que os objetivos do curso foram atingidos. Para isso, 87,5\% dos professores cursistas tiveram uma compreensão de como o curso foi impactante e desafiador para sua prática pedagógica; já 12,5\% dos entrevistados disseram ter dificuldade em entender a proposta do curso, em função da não utilização do aplicativo da Google.

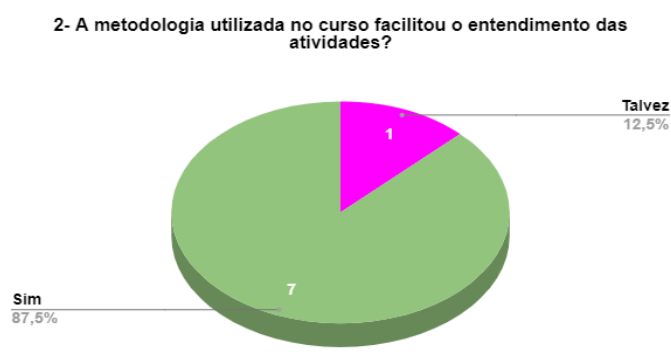

Gráfico 2: A metodologia utilizada no curso facilitou o entendimento das atividades?

Fonte: elaborado pelas autoras (2017) 


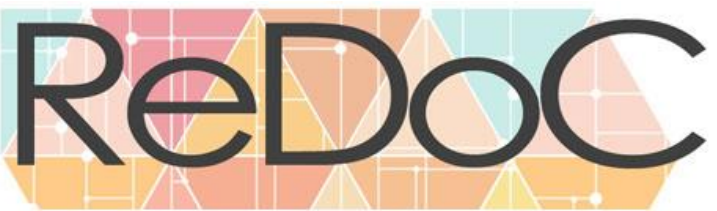

Revista Docência e Cibercultura

O gráfico 2 apresenta a metodologia utilizada no curso facilitou o entendimento das atividades. Pode-se constatar nessa informação que $87,5 \%$ dos professores cursistas apresentam satisfação na execução de nova metodologia, refutando a vontade de conhecer o novo. Entretanto, 12,5\% dos professores cursistas afirmam que talvez a metodologia utilizada possa ser utilizada na consolidação dos conhecimentos do curso.

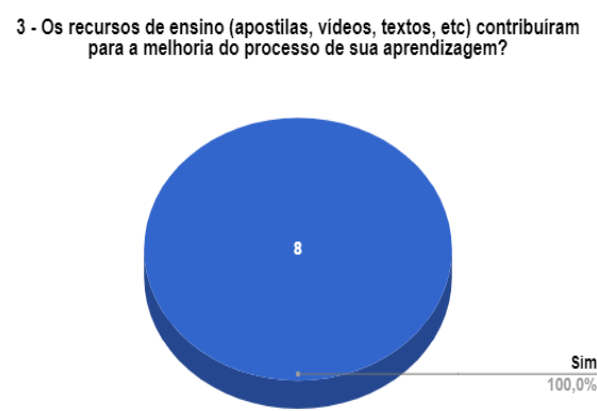

Gráfico 3: Os recursos de ensino contribuíram para a melhoria do processo de sua aprendizagem?

Fonte: elaborado pelas autoras (2017)

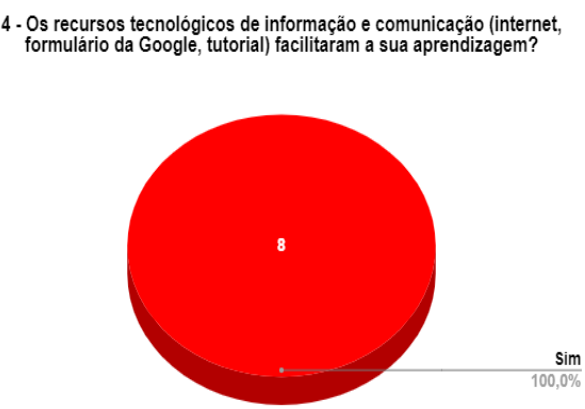

Gráfico 4: Os recursos tecnológicos de informação e comunicação facilitaram a sua aprendizagem?

Fonte: elaborado pelas autoras (2017)

Os resultados referentes aos gráficos 3 e 4, também são idênticos, ou seja, 100\% dos professores cursistas disseram sim, que os recursos tecnológicos devem servir para enriquecer o ambiente educacional, também contribuir para aprimorar e auxiliar o trabalho em sala de aula de forma criativa e dinâmica proporcionando e despertando mudanças na prática pedagógica dos professores, a partir da construção do conhecimento.

\section{CONSIDERAÇÕES FINAIS}

As tecnologias ligadas à educação promovem a motivação, interação e a melhoria do processo de ensino e aprendizagem. Portanto, para que os docentes sejam inseridos no mundo digital, os mesmos precisam ser capacitados para atender às demandas de uma nova forma de aprender e ensinar, entretanto percebemos para além da capacitação que envolve as questões pedagógicas como: falta de cultura digital, interação entre os cursistas 


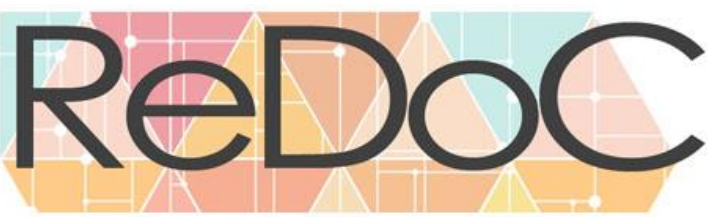

Revista Docência e Cibercultura

e o tutor, morosidade de feedback das atividades, entre outros, é a infraestrutura dos ambientes onde os cursos são oferecidos tomando como exemplo acesso a internet.

Desta feita, é preciso construir um ambiente de desenvolvimento profissional que deva proporcionar o letramento digital, aprendizado social e colaborativo do docente para manter ativos e relevantes no processo pedagógico e tecnológico.

Portanto, é importante acentuar que este trabalho não tem a intencionalidade de apontar solução para a formação de professores, mas despertar e provocar discussões sobre o tema Upgrade na interface do formulário online da Google: ambiente colaborativo de aprendizagem e apresentar alternativas de cunho pedagógico e tecnológico dos recursos demonstrados.

\section{REFERÊNCIAS}

ALMEIDA, Aline Castro. Planos de ação pessoal utilizando as ferramentas da Google. Disponível em: 〈http://innovatorbrasil.com.br/planolinechan/>. Acesso em: 18 de nov. de 2017.

BRASIL/CAPES. Disponível em <http://www.capes.gov.br/educacao>. Acesso em: 20 de nov. de 2017.

Constituição da República Federativa do Brasil. Promulgada em 5 de outubro de 1988. Brasília, 1988.

Lei de Diretrizes e Bases da Educação Nacional (LDBEN). Lei nº 9.394, de 20 de dezembro de 1996.

MEC. Portaria $n^{\circ} 1.328$, de 23 de setembro de 2011. Disponível em: $<$ http://portal.mec.gov.br/secretaria-de-regulacao-e-supervisao-da-educacao-superiorseres/legislacao-e-atos-normativos>. Acesso em: 20 de nov. de 2017.

Plano Nacional de Educação 2014-2024 (PNE). Lei no 13.005, de 25 de junho de 2014. Brasília: Câmara dos Deputados, Edições Câmara, 2014. Disponível em Disponível em: <http://portal.mec.gov.br/secretaria-de-regulacao-e-supervisao-daeducacao-superior-seres/legislacao-e-atos-normativos>. Acesso em: 20 de nov. de 2017.

CANDAU, Vera Maria Ferrão. Formação de educadores: uma perspectiva multidimensional. Em Aberto. v. 1, n. 8, 2011. 
CRESWELL, J. W. (2007). Projeto de pesquisa: métodos qualitativo, quantitativo e misto (2a ed., L. de O. Rocha, Trad.). Porto Alegre: Artmed. (Obra original publicada em 2003).

CRESWELL, J. W.; PLANO CLARK, V. L. Designing and conducting mixed methods research. 2nd. Los Angeles: SAGE Publications, 2011.

LITWIN, Edith. Tecnologia Educacional - Política, História e Propostas. Porto Alegre: Artes Médicas, 1997.

MATTAR, João. Tutoria e interação em educação a distância. São Paulo: Cengage Learning, 2012.

MOREIRA, Marco Antônio. O que é afinal aprendizagem significativa. Disponível em $<$ http://moreira.if.ufrgs.br/oqueeafinal.pdf>. Acesso em 03 de jan. de 2018.

OLIVEIRA, Aldemir M. A utilização do iniciador da Google como ferramenta no processo avaliativo em matemática uma experiência no Amazonas - região norte do Brasil. Educação Matemática na Contemporaneidade: desafios e possibilidades - São Paulo - SP - 2016.

ROESLER, Rafael. Web 2.0, interações sociais e construção do conhecimento. VII SIMPED- Simpósio Pedagógico e Pesquisa em Educação - 2012.

SILVA, Thalita. A usabilidade da plataforma e-Proinfo: Um estudo acerca do uso das ferramentas da plataforma utilizada no Curso Piloto de Administração a Distancia da UFAL. Disponível em: <http://recursos.portaleducoas.org/sites/default/files/2258.pdf>. Acesso em: 18 de nov. de 2017.

ZABALA, Antony. Como trabalhar os conteúdos procedimentais em aula. Porto Alegre: Artmed, 2002. 